\title{
Engineering of Refractive Index in Sulfide Chalcogenide Glass by Direct Laser Writing
}

\author{
Yaping Zhang, Yangqin Gao, Tien K. Ng, and Boon S. Ooi ${ }^{\dagger}$ \\ Division of Physical Sciences and Engineering, King Abdullah University of Science and Technology (KAUST), \\ Thuwal 23955-6900, Saudi Arabia \\ Basil Chew and Mohamed Nejib Hedhili \\ Advanced Nanofabrication, Imaging and Characterization Core Facilities, \\ King Abdullah University of Science and Technology (KAUST), Thuwal 23955-6900, Saudi Arabia \\ Donghui Zhao and Himanshu Jain \\ International Materials Institute for New Functionality in Glass, Department of Materials Science and Engineering, \\ Lehigh University, Bethlehem PA 18015, USA
}

\begin{abstract}
Arsenic trisulfide $\left(\mathrm{As}_{2} \mathrm{~S}_{3}\right)$ glass is an interesting material for photonic integrated circuits (PICs) as infrared (IR) or nonlinear optical components. In this paper, direct laser writing was applied to engineer the refractive index of $\mathrm{As}_{2} \mathrm{~S}_{3}$ thin film. Film samples were exposed to focused above bandgap light with wavelength at $405 \mathrm{~nm}$ using different fluence adjusted by laser power and exposure time. The index of refraction before and after laser irradiation was calculated by fitting the experimental data obtained from Spectroscopic Ellipsometer (SE) measurement to Tauc-Lorenz dispersion formula. A positive change in refractive index $(\Delta n=0.19$ at $1.55 \mu \mathrm{m}$ ) as well as an enhancement in anisotropy was achieved in $\mathrm{As}_{2} \mathrm{~S}_{3}$ film by using $10 \mathrm{~mW}, 0.3 \mu \mathrm{s}$ laser irradiation. With further increasing the fluence, refractive index increased while anisotropic property weakened. Due to the rapid and large photo-induced modification of refractive index obtainable with high spatial resolution, this process is promising for integrated optic device fabrication.
\end{abstract}

\section{INTRODUCTION}

Chalcogenide glasses ( $\mathrm{S}$, Se, Te based glasses) exhibit attractive optical properties including high refractive index, large nonlinearities, and excellent transmission at infrared wavelength [1-3]. As amorphous semiconductors, chalcogenide glasses are well known to show structural modification when exposed to near band gap light, typically at visible wavelengths $[4,5]$. Distinct photo-induced phenomena such as photo darkening [6], photo fluidity [7], photo anisotropy [8] and so forth can be observed, which are accompanied by changes in the optical constants [9]. The ability to optical writing and thermally erase structures, combined with transparency in the infrared region and high nonlinearities, make chalcogenide glasses suitable for thin film optical applications. In addition, chalcogenide glasses are promising as laser and amplifier media, as they are potentially good hosts for rare-earth ions. Their low phonon energy leads to low non-radiative decay rates and their high refractive index leads to high stimulated emission cross sections $[10,11]$.

In the present work, arsenic trisulfide $\left(\mathrm{As}_{2} \mathrm{~S}_{3}\right)$ glass is used and examined mainly, since this glass possesses reproducible physical properties, and also the energy gap of $2.4 \mathrm{eV}$ is suitable for optical experiment [12]. Several components for building complex photonic integrated circuits (PICs) have been demonstrated in arsenic trisulfide $\left(\mathrm{As}_{2} \mathrm{~S}_{3}\right)$ glass [13-15]. Exposure by He-Ne [16], Ti: sapphire [17], argon ion [18], and other lasers [19] have been used to create structures, such as gratings and waveguides. Lamp sources have also been used with success [20].

In order to use chalcogenide glasses in integrated optics, it is important to know the optical constants especially the refractive index and how they can be engineered with illumination. Above band-gap illumination can have far more prominent effects than that of the near band-gap illumination due to the greater absorption and provide lasting optical and geometrical changes, which can be advantageous for the fabrication of micro-optic components [21]. In this paper, we report on the laser irradiation induced change in refractive index and anisotropic property of $\mathrm{As}_{2} \mathrm{~S}_{3}$ thin film using by a $405 \mathrm{~nm}$ UV direct writing technique.

\section{EXPERIMENTAL}

Commercially obtained $\mathrm{As}_{2} \mathrm{~S}_{3}$ bulk glass (Amorphous Material) was deposited onto microscope glass slide substrates (fused silica with thickness of $1 \mathrm{~mm}$ ) by thermal evaporation (Edwards Coating System E306A) in a vacuum of $\sim 1 \times 10^{-6}$ Torr. The deposition rate was $\sim 10 \AA / \mathrm{s}$, continuously measured using a quartz crystal rate/thickness monitor (Sigma Instruments SQM-160). It is well known that such a low deposition rate produces film composition that is very close to the starting bulk materials [22]. The total thickness of the film was about $2.0 \mu \mathrm{m}$.

A $6 \mathrm{~mm} \times 6 \mathrm{~mm}$ region on $\mathrm{As}_{2} \mathrm{~S}_{3}$ films was directly written by the $405 \mathrm{~nm}$ UV laser ( $\mu \mathrm{PG} 101$ Mask Laser Writer, Heidelberg) with raster scanning at a fixed speed of $100 \mathrm{~mm} / \mathrm{s}$. The pixel size is $1 \mu \mathrm{m}$ and there are 8 pixels in one scan. The laser spot size on the film is $2.5 \mu \mathrm{m}$. Different powers $(10 \mathrm{~mW}$ and $20 \mathrm{~mW})$ and exposure time $(0.1 \mu \mathrm{s}$, $0.3 \mu \mathrm{s}$, and $0.5 \mu \mathrm{s}$ ) was selected for adjusting the fluence. The surface features of $\mathrm{As}_{2} \mathrm{~S}_{3}$ films before and after laser writing was observed under an optical microscope (Nikon Eclipse L200). 


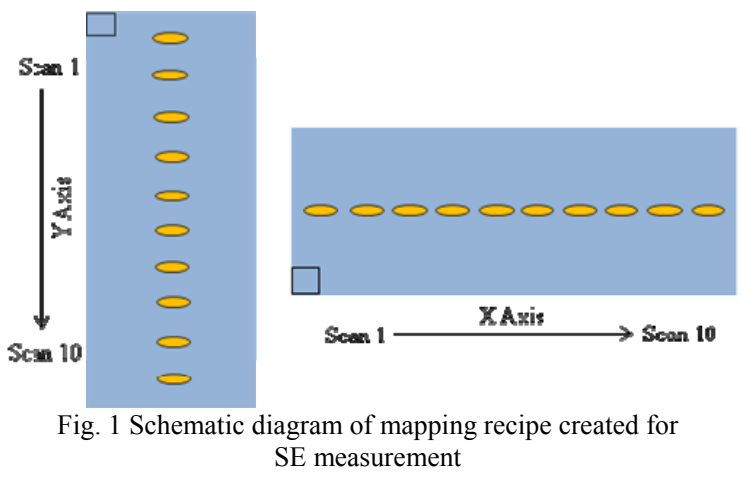

The Spectroscopic Ellipsometer (SE) measurements were made at an angle of incidence of $70^{\circ}$ with a $1 \mathrm{~mm} \times 3 \mathrm{~mm}$ elliptic light spot, using the Jobin-Yvon Horiba Uvisel Spectroscopic Ellipsometer (UVISEL LT AGMS, 210$2100 \mathrm{~nm}$ ) with a Xe-lamp. Measurements were carried out across the spectral range of $0.6-2.5 \mathrm{eV}(496-2067 \mathrm{~nm})$, with $0.05 \mathrm{eV}$ steps and $300 \mathrm{~ms}$ of integration time. The optical constants, refractive index $(n)$, extinction coefficient $(k)$ and optical band-gap energy $\left(E_{g}\right)$ were computed from the experimental angle $(\Psi)$ and phase change $(\Delta)$ using the instrument's software (DeltaPsi2 from Jobin-Yvon). The Tauc-Lorenz dispersion formula was used to model the optical constants of $\mathrm{As}_{2} \mathrm{~S}_{3}$ films before and after laser writing [23]. The varying parameters for fitting were the thickness of the thin film layers, the chalcogenide volume fraction of the roughness layers and the optical constants of the chalcogenide material. The best sample model obtained based on the lowest $\chi^{2}$ parameter (using a Marquardt minimization algorithm) which reflects the quality of fitting includes a roughness layer on top of the thin film as well as a film/substrate interface layer, with initial chalcogenide volume fractions of $50 \%$ plus $50 \%$ void. To avoid the backside reflection of the polished $\mathrm{SiO}_{2}$ substrate, a void layer underneath the substrate was added in the model as well. A mapping recipe was created to measure samples along two directions which are perpendicular to each other as shown in Fig. 1. In order to minimize the influence of environment on the optical constants of $\mathrm{As}_{2} \mathrm{~S}_{3}$ films, all measurements were performed in dark.

\section{RESULTS AND DisCUSSIONS}

Fig. 2 represents the experimental and fitted $\Psi$ values for as-deposited $\mathrm{As}_{2} \mathrm{~S}_{3}$ film SA1, as well as the calculated $n$ and $k$ curves. UV filter with cut-off edge at $400 \mathrm{~nm}$ was used during the measurements. The $\Psi$ and $\Delta$ are related to the parallel $\left(r_{s}\right)$ and perpendicular $\left(r_{p}\right)$ Fresnel reflection amplitude coefficient [24].

$$
f_{p}=\tan \psi \exp (s)
$$

The $n$ and $k$ values were then computed by the instrument software from $r_{s}$ and $r_{p} . E_{g}, n_{\lambda=1.55 \mu \mathrm{m}}$ and $\chi^{2}$ values are summarized in Table 1. As shown in Table 1, the $\chi^{2}$ values for both $\mathrm{Y}$ direction and $\mathrm{X}$ direction mapping are almost below 1.5, indicating the model adapts to the fitting very well. The $E_{g}$ and $n_{\lambda=1.55 \mu \mathrm{m}}$ obtained after fitting are close to the data reported in literature [9]. It can be concluded that
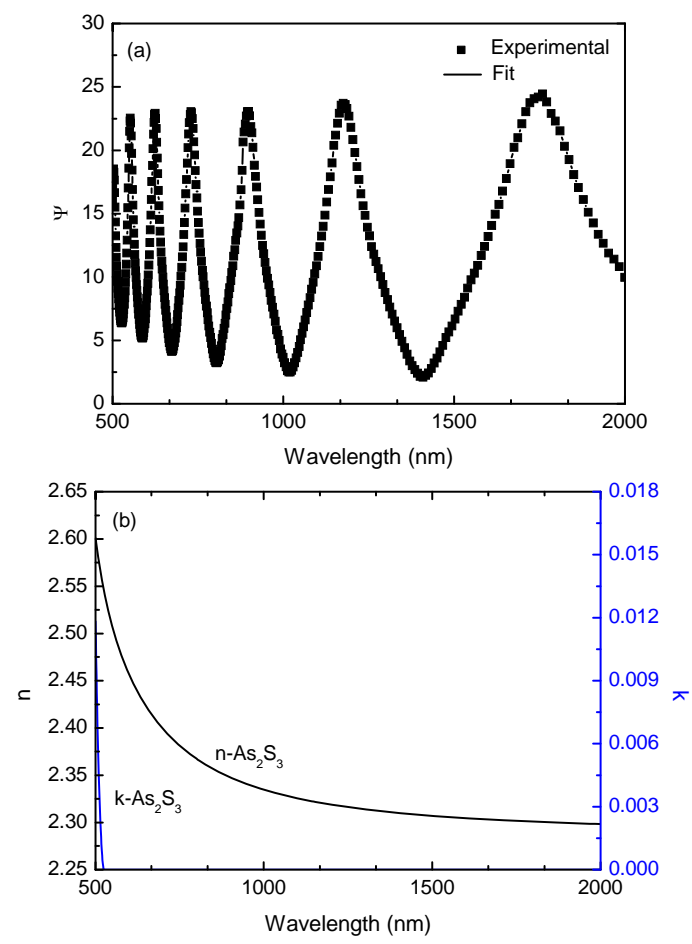

Fig. 2 (a) Experimental (dots) and fitted (curve) $\Psi$ values for as-deposited $\mathrm{As}_{2} \mathrm{~S}_{3}$ film SA1

(b) Correspondent calculated $n$ and $k$

the as-deposited $\mathrm{As}_{2} \mathrm{~S}_{3}$ film is of good uniformity; however, a negative difference of about 0.02 between $\mathrm{X}$ direction and $\mathrm{Y}$ direction in refractive index should be noted.

Fig. 3 shows $n_{\lambda=1.55 \mu \mathrm{m}}$ of as-deposited $\mathrm{As}_{2} \mathrm{~S}_{3}$ film SA2 obtained by fitting data measured with and without UV filter. It can be seen that $n_{\lambda=1.55 \mu \mathrm{m}}$ increased as much as 0.10 when the SE measurement was carried out on the same spot without UV filter for successive three times scans, however, the variation of $n_{\lambda=1.55 \mu \mathrm{m}}$ is little in the case of using UV filter. The results indicate $\mathrm{As}_{2} \mathrm{~S}_{3}$ is very sensitive to $\mathrm{UV}$ light. Therefore, all the SE measurements for samples after direct laser writing were made with UV filter.

$n_{\lambda=1.55 \mu \mathrm{m}}$ of as-deposited $\mathrm{As}_{2} \mathrm{~S}_{3}$ films SA1 and SA3, SA4, SA5 and SA6 after direct laser writing using different power and exposure time are shown in Fig. 4. It is obvious that refractive index increased significantly after laser irradiation. The change in refractive index is dependent on the irradiation fluence (power intensity times exposure time) to a large degree. The increase in refractive index obtained

TABLE I

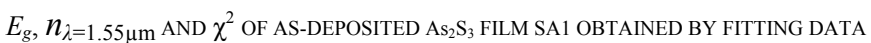
MEASURED WITH UV FILTER USING MAPPING RECIPE

\begin{tabular}{|c|c|c|c|c|c|c|}
\hline \multirow{2}{*}{$\begin{array}{c}\text { Scan } \\
\text { sequence }\end{array}$} & \multicolumn{3}{|c|}{ Y direction } & \multicolumn{3}{c|}{ X direction } \\
\cline { 2 - 7 } & $E_{g}$ & $n$ & $\chi^{2}$ & $E_{g}$ & $n$ & $\chi^{2}$ \\
\hline 1 & 2.361 & 2.316 & 1.634 & 2.335 & 2.292 & 1.486 \\
\hline 2 & 2.363 & 2.315 & 1.535 & 2.364 & 2.292 & 1.391 \\
\hline 3 & 2.321 & 2.312 & 1.395 & 2.277 & 2.290 & 1.295 \\
\hline 4 & 2.264 & 2.312 & 1.252 & 2.364 & 2.289 & 1.417 \\
\hline 5 & 2.335 & 2.308 & 1.295 & 2,259 & 2.289 & 1.219 \\
\hline 6 & 2.359 & 2.309 & 1.228 & 2.331 & 2.288 & 1.297 \\
\hline 7 & 2.359 & 2.307 & 1.176 & 2.340 & 2.288 & 1.334 \\
\hline 8 & 2.193 & 2.307 & 1.173 & 2.363 & 2.289 & 1.308 \\
\hline 9 & 2.357 & 2.306 & 1.125 & 2.344 & 2.287 & 1.399 \\
\hline
\end{tabular}




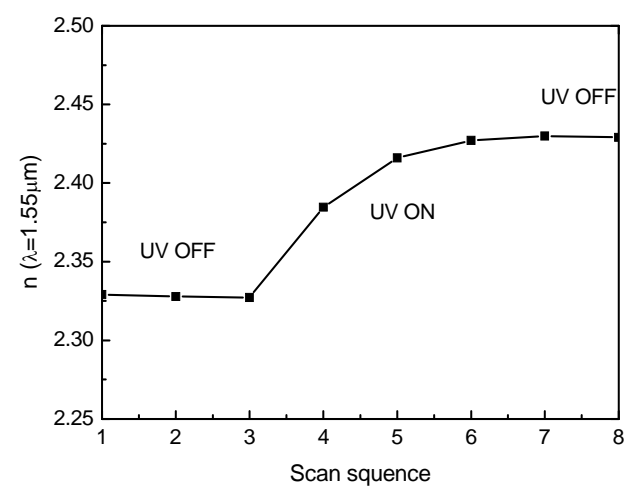

Fig. $3 n_{\lambda=1.55 \mu \mathrm{m}}$ of as-deposited $\mathrm{As}_{2} \mathrm{~S}_{3}$ film SA2 obtained by fitting data

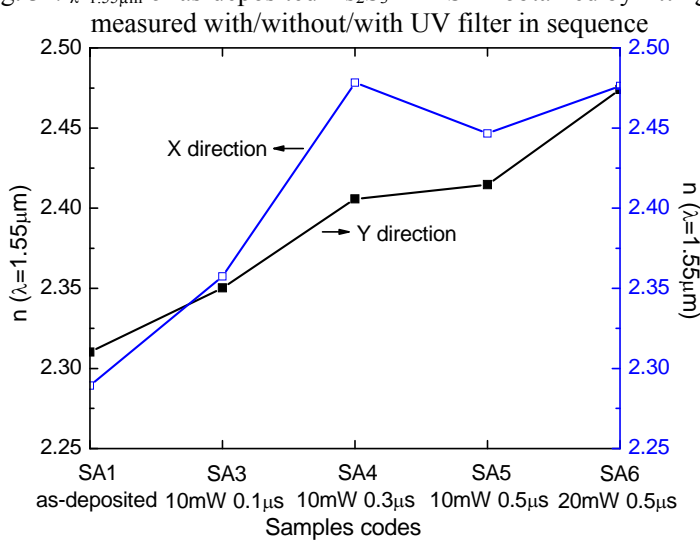

Fig. $4 n_{\lambda=1.55 \mu \mathrm{m}}$ of as-deposited $\mathrm{As}_{2} \mathrm{~S}_{3}$ film SA1 and SA3, SA4, SA5 SA6 after direct laser writing

along $\mathrm{X}$ direction is as high as 0.19 with increasing the exposure time to $0.3 \mu \mathrm{s}$ at a fixed power of $10 \mathrm{~mW}$ while 0.10 increases are obtained along $\mathrm{Y}$ direction.

As seen in Fig. 4, increasing the exposure time to $0.5 \mu \mathrm{s}$ with the same irradiation power did not increase the refractive index much. With the increase of irradiation power, refractive index increased in both $\mathrm{X}$ and $\mathrm{Y}$ direction. In addition, the increase in refractive index obtained along $X$ direction is higher than that obtained along Y direction after laser irradiation, resulting in a positive difference in refractive index between $\mathrm{X}$ direction and $\mathrm{Y}$ direction which is opposite to the as-deposited sample. The difference in refractive index between $\mathrm{X}$ and $\mathrm{Y}$ direction becomes inconspicuous when $\mathrm{As}_{2} \mathrm{~S}_{3}$ film was irradiated by $20 \mathrm{~mW}$, $0.5 \mu$ s laser.

The effects induced in amorphous chalcogenides by UV irradiation are similar to the case of photo-induced phenomena with band-gap irradiation. But the rate of change for the UV irradiation is two orders of magnitude higher than that for the band-gap irradiation. Because an Auger process may participate in the case of UV irradiation while in the case of band-gap irradiation the photo-induced phenomena are caused by the changes in atomic coordinations and positions resulting from exciting lone-pair electrons. By using UV irradiation, inner core holes can be immediately filled by outer electron with Auger process which could induce more holes in upper states (bonding and lone-pair states), since one Auger process creates two holes(vacancy cascade process) [9]. In this situation, bond

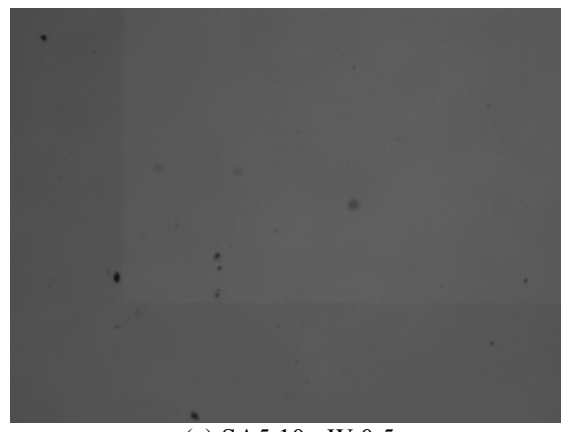

(a) SA5 $10 \mathrm{~mW} 0.5 \mu \mathrm{s}$

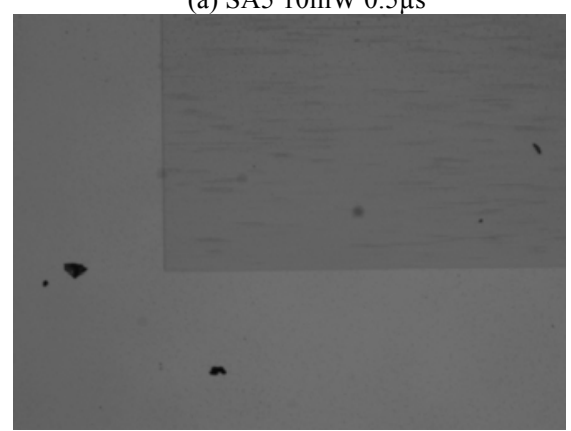

(b) SA6 20mW $0.5 \mu \mathrm{s}$

Fig. 5 Surface morphology of SA5 and SA6 after direct laser writing $(20 \times)$ breaking or ionization is easy to occur, leading to a change in local structure order in amorphous network. Moreover, strong UV absorption occurs in chalcogenide glasses. According to the Kramers-Kronig relations [25]

$$
\Delta n_{2}=\frac{1}{2 \pi} \int_{0}^{\infty} \frac{\Delta u(\pi) u \lambda}{1-\left(\frac{\lambda}{\lambda}\right)^{2}}
$$

where $\lambda$ is the free space wavelength and $\Delta \mathrm{n}(\lambda)$ relates the change in refractive index to changes in the absorption coefficient $\Delta \alpha(\lambda)$. Hence, a higher absorption in the UV results in a positive index change. Thus, higher increase in refractive index after UV irradiation is understandable.

The difference in refractive index between $\mathrm{X}$ direction and $\mathrm{Y}$ direction might be due to the optical anisotropy of chalcogenide glasses. Thin planar $\mathrm{As}_{2} \mathrm{~S}_{3}$ optical waveguides possess anisotropy of the refractive index of about 0.01 [9]. The anisotropy can be controlled by additional illumination that induces photo-structural change in the material since optically anisotropic entities existing in $\mathrm{As}_{2} \mathrm{~S}_{3}$ network structure can be re-orientated by polarized light $[8,26]$. Thus, with increasing the fluence of laser irradiation, the reoriented entities increased, resulting in enhancement in anisotropy of refractive index. This particular property allows for creating special band waveguides, grating structures, and other passive or active elements [9]. However, heating effect would become huge while the fluence is high since irradiated region can be physically distinguished under microscope when using laser power of $10 \mathrm{~mW}$ and exposure time of $0.5 \mu \mathrm{s}$. As shown in Fig. 5, the irradiated region is even more noticeable with laser power increased to $20 \mathrm{~mW}$. Although the refractive index increased 
in both directions, it might be induced by the densification of laser irradiated region $[27,28]$. The significant increase of temperature may cause melting of irradiated region, leading to the re-construction of amorphous network instead of reorientation of optical anisotropic entities. Therefore, the difference in refractive index between $\mathrm{X}$ direction and $\mathrm{Y}$ direction decreased. Moreover, the heating effect will cause evaporation and oxidation, exerting negative impact on properties of amorphous chalcogenide films and affecting the performance of optical components ultimately.

\section{CONCLUSIONS}

Direct laser writing with wavelength at $405 \mathrm{~nm}$ was applied for engineering of refractive index in arsenic trisufide $\left(\mathrm{As}_{2} \mathrm{~S}_{3}\right)$ thin films thermally evaporated on fused silica substrates. Tauc-Lorenz dispersion formula was used to obtain optical constants through modeling experimental data obtained from spectroscopic ellipsometer. The refractive index increased with increase of UV light fluence. The difference of refractive index obtained along directions perpendicular to each other indicated anisotropic property in $\mathrm{As}_{2} \mathrm{~S}_{3}$ films, which was enhanced by fluence as well. However, heating effect become significant with further increasing the fluence, resulting in weakened anisotropy of refractive index. Thus, high increase in refractive index and anisotropic property of $\mathrm{As}_{2} \mathrm{~S}_{3}$ film can be obtained by direct UV laser writing with optimized irradiation parameter. Together with high resolution achievable, this process is promising for the fabrication of integrated optics.

\section{ACKNOWLEDGMENT}

The work is supported by a joint program between KAUST and University of Michigan, Ann Arbor, under KAUST- Academic Excellence Alliance (AEA) 2010 Grant.

\section{REFERENCES}

[1] J.A. Savage, "Optical properties of chalcogenide glasses," J. NonCryst. Solids, vol. 47, pp. 101-116, 1982.

[2] K. Petkov and P.J.S. Ewen, "Photoinduced changes in the linear and non-linear optical properties of Chalcogenide glasses," J. NonCryst. Solids, vol. 249, pp. 150-159, 1999.

[3] A. Zakery and S.R. Elliott, "Optical properties and applications of chalcogenide glasses: a review," J. Non-Cryst. Solids, vol. 330, pp. 1-12, 2003.

[4] K. Shimakawa, A. Kolobov, and S.R. Elliott, "Photoinduced effects and metastability in amorphous semiconductors and insulators," Adv. Phys., vol. 44, pp. 475-588, 1995.

[5] Alexander.V. Kolobov and Kazunobu Tanaka, "Photoinduced Metastability in Amorphous Semiconductors", J. Optoelectron. Adv. M., vol. 1, pp. 3-20, 1999

[6] J.P. DeNeufville, S.C. Moss, and S.R. Ovshinsky, "Photostructural transformations in amorphous $\mathrm{As}_{2} \mathrm{Se}_{3}$ and $\mathrm{As}_{2} \mathrm{~S}_{3}$ films," J.NonCryst.Solids, vol. 13, pp. 191-223, 1973/74.

[7] H. Hisakuni and K. Tanaka, "Optical Microfabrication of Chalcogenide Glasses," Science, vol. 270, pp. 974-975, 1995.

[8] H. Fritzsche, "Optical anisotropies in chalcogenide glasses induced by band-gap light," Phys. Rev. B, vol. 52, pp. 15854-15861, 1995.

[9] Mihai A. Popescu, Non-Crystalline Chalcogenides, Kluwer Academic Publishers, Netherlands, 2002.

[10] D. Coleman, P. Golding, T. A. King, and S. D.J ackson, "Spectroscopic and energy transfer parameters for $\mathrm{Er}^{3+}$ doped and $\mathrm{Er}^{3+}, \mathrm{Pr}^{3+}$ co-doped GeGaS glasses,"' J. Opt. Soc. Am. B, vol. 17, pp. 1982-1989, 2002.

[11] A. J. Kenyon, "Recent developments in rare-earth doped materials for optoelectronics," Prog. Quant. Electron., vol. 26, pp. 225-284, 2002.

[12] K. Morigaki, Physics of Amorphous Semiconductors, Imperial College, London, 1999.

[13] A. Saliminia, A. Villeneuve, T. V. Galstyan, S. LaRochelle, and K. Richardson, "First- and second-order Bragg gratings in single-mode planar waveguides of chalcogenide glasses," J. Lightwave Technol., vol.17, pp. 837-842, 1999.

[14] C. Gmachl, H. Y. Hwang, R. Paiella, D. L. Sivco, J. N. Baillargeon, F. Capasso, and A. Y. Cho, "Quantum cascade lasers with low-loss chalcogenide lateral waveguides," IEEE Photon. Technol. Lett., vol. 13, pp. 182-184, 2001.

[15] Vahid G. Ta'eed, Neil J. Baker, Libin Fu, Klaus Finsterbusch, Michael R.E. Lamont, David J. Moss, et al, "Ultrafast all-optical chalcogenide glass photonic circuits," Opt. Express, vol. 15, pp. 9205-9221, 2007.

[16] A.C. van Popta, R.G. DeCorby, C.J. Haugen, T. Robinson,and J.N. McMullin, "Photoinduced refractive index change in As2Se3 by 633nm illumination,” Opt.Express, vol. 10, pp. 639-644, 2002.

[17] H. Nicolas, J.M. Laniel, R. Valle, and A. Villeneuve, "Photosensitivity of $\mathrm{As}_{2} \mathrm{~S}_{3}$ chalcogenide thin films at $1.5 \mu \mathrm{m}$," Opt. Lett., vol. 28, pp. 965-967, 2003.

[18] Qiming Liu and Fuxi Gan, "Photobleaching in amorphous $\mathrm{GeS}_{2}$ thin films," Mater.Lett., vol. 53, pp. 411-414, 2002.

[19] H.-Y. Lee and T. Yao, "Wet-etching selectivity of Ag-photodoped AsGeSeS thin films and the fabrication of a planar corrugated onedimensional photonic crystal by a holographic method," J. Vac. Sci. Tech. B, vol. 20, pp. 2017-2023, 2002.

[20] T. Wágner, M. Frumar, Mir. Vlček, S. O. Kasap, and Mil. Vlček, "The tailoring of the composition of Ag-As-Se amorphous films using optically-induced solid state reaction between $\mathrm{Ag}$ and $\mathrm{As}_{30} \mathrm{Se}_{70}$ films." Int.J. Inorg. Mater., vol. 3, pp. 497-501, 2001.

[21] A.K. Mairaj, P. Hua, H.N. Rutt, and D.W. Hewak, "Fabrication and Characterization of Continuous Wave Direct UV $(\lambda=244 \mathrm{~nm})$ Written Channel Waveguides in Chalcogenide (Ga:La:S) Glass," $J$. Lightwave Technol., vol. 20, pp. 1578-1584, 2002.

[22] A. Kovalskiy, A. C. Miller, H. Jain, and M. Mitkova, "In-situ measurements of $x$-ray induced silver diffusion into $\mathrm{Ge}_{30} \mathrm{Se}_{70}$ thin film," J. Am. Ceram. Soc., vol. 91, pp. 760-765, 2008.

[23] G.E. Jellison Jr. and F.A. Modine, "Parameterization of the optical functions of amorphous materials in the interband region," Appl. Phys. Lett., vol. 69, pp. 371-373, 1996.

[24] H.A. Kramers, Collected Scientific Papers, North-Holland, Netherlands, 1956.

[25] R.M.A. Azzam and N.M. Bashara, Ellipsometry and Polarized Light, North-Holland, Netherlands, 1989.

[26] K. Tanaka, K. Ishida, and N. Yoshida, "Mechanism of photoinduced anisotropy in chalcogenide glasses," Phys. Rev. B, vol. 54, pp. 9190-9195, 1996.

[27] H.G. Limberger, P.Y. Fonjallaz, R.P. Salathe, and F. Cochet, "Compaction-and photoelastic-induced index changes in fiber bragg gratings," Appl. Phys. Lett., vol. 68, no. 22, pp.3069-3071, 1996

[28] K. Miura, Jianrong Qiu, H. Inouye, T. Mitsuyu, and K. Hirao, "Photowritten optical waveguides in various glasses with ultrashort pulse laser," Appl. Phys. Lett., vol. 73, pp. 3329-3331, 1997. 